\title{
Does men's advantage in mental rotation persist when real three-dimensional objects are either felt or seen?
}

\author{
MICHÈLE ROBERT and ELIANE CHEVRIER \\ Université de Montréal, Montréal, Québec, Canada
}

\begin{abstract}
In several spatial tasks in which men outperform women in the processing of visual input, the sex difference has been eliminated in matching contexts limited to haptic input. The present experiment tested whether such contrasting results would be reproduced in a mental rotation task. A standard visual condition involved two-dimensional illustrations of three-dimensional stimuli; in a haptic condition, three-dimensional replicas of these stimuli were only felt; in an additional visual condition, these replicas were seen. The results indicated that, irrespective of condition, men's response times were shorter than women's, although accuracy did not significantly differ according to sex. For both men and women, response times were shorter and accuracy was higher in the standard condition than in the haptic one, the best performances being recorded when full replicas were shown. Self-reported solving strategies also varied as a function of sex and condition. The discussion emphasizes the robustness of men's faster speed in mental rotation. With respect to both speed and accuracy, the demanding sequential processing called for in the haptic setting, relative to the standard condition, is underscored, as is the benefit resulting from easier access to depth cues in the visual context with real three-dimensional objects.
\end{abstract}

To conduct their seminal work on mental rotation processes, Shepard and Metzler (1971) created a collection of two-dimensional line drawings of three-dimensional objects, each made of small cubes composing a rather complex shape. Typically, participants are shown a pair of such computerized drawings, each in a different orientation; in order to decide whether the drawings are identical or not, they must mentally turn the illustrated forms around their central axes and align them. However, as has been revealed by meta-analytic reviews (Linn \& Petersen, 1985; Voyer, Voyer, \& Bryden, 1995), men consistently take less time than women in carrying out such visuospatial comparisons, whereas accuracy, which is generally high across sexes, may also be superior in men.

A preliminary version of this report was presented at the meeting of the Canadian Society for Brain, Behaviour, and Cognitive Science, Quebec City, June 2001. This study was supported by Grant 2602 from the Natural Sciences and Engineering Research Council of Canada to the first author. The report is based on a thesis by the second author in partial fulfillment of the requirements for the master's degree at the Université de Montréal. During her master's studies, the second author was supported by a scholarship from the Université de Montréal. We are grateful to Edouard Gentaz for ingenious conceptual and procedural suggestions, to Jacques Berrichon for technical expertise in building valid and sturdy three-dimensional wooden replicas of the illustrated stimuli, and to François Berthiaume for helpful comments on the manuscript. We also acknowledge the assistance of Sébastien Hélie with data preparation for statistical analysis. Correspondence concerning this article should be addressed to M. Robert, Département de psychologie, Université de Montréal, Montréal, Québec H3C 3J7, Canada (e-mail: michele.robert@umontreal.ca).

\section{Sex Differences in Visual Tasks}

Shepard and Metzler's (1971) illustrations were reproduced by Vandenberg and Kuse (1978) in devising the Mental Rotations Test. In this now common paper-andpencil assessment of the skills involved, the participants are allowed limited time to complete a series of items, in each of which they must find the two response choices, among the four offered, that are identical to a target shape despite being differently oriented. The greater male accuracy measured under this timed condition is the most substantial of the sex differences observed in visuospatial contexts (Voyer et al., 1995). Remarkably robust, it has proven stable in Western societies over a 20 -year period (Masters \& Sanders, 1993) and is also manifest in African and Asian populations (Amponsah, 2000; Li, Nuttall, \& Zhu, 1999; Mann, Sasanuma, Sakuma, \& Masaki, 1990).

Few of the researchers in this literature have used an untimed procedure, and none has assessed response time with this procedure. Some of these authors have recorded no significant sex differences in accuracy (Goldstein, Haldane, \& Mitchell, 1990; Voyer, 1997), whereas others have reported higher scores in men (Masters, 1998; Resnick, 1993). Voyer's (2001) meta-analysis (conducted on a small number of studies, including unpublished ones) has shown that the magnitude of the sex difference in accuracy is reduced when no time limits are used. From their review of timed and untimed contexts, Linn and Petersen (1985) concluded that men's primary advantage in mental rotation lies in their greater response speed, although they indicated that this sex difference 
could additionally reflect a male preference for more efficient strategies and lower cautiousness. In the present experiment, response speed was measured when no time limit was imposed.

The male superiority has been shown to be limited to visual settings in other spatial tasks - for example, adjusting a tilted bar vertically or horizontally within a tilted grid (Walker, 1972), representing a liquid surface as horizontal in a tipped container (Robert \& Longpré, 2002; Robert, Pelletier, St-Onge, \& Berthiaume, 1994), or reproducing previously seen hill inclinations (Proffitt, Bhalla, Gossweiler, \& Midgett, 1995). No significant sex differences were found in haptic conditions in which blindfolded participants (with normal vision) performed these tasks while relying exclusively on tactile and proprioceptive information supplied by their hand (and arm) movements. Hence, it is worthwhile establishing whether mental rotation achievement also fails to exhibit sex differences when Vandenberg and Kuse's (1978) task is carried out haptically.

\section{Haptic Processing}

The hand is a skilled perceptual device that can move along the vertical, horizontal, and depth planes in Euclidean space. It works independently from visual input. Relying on cutaneous and kinesthetic (involving muscles, tendons, and joints) mechanoreceptors (Hatwell, 1990; Lederman \& Klatzky, 1998; Loomis \& Lederman, 1986), the hand grasps information about the properties, including properties of a geometric nature, such as size and shape, and the spatial relations of objects. The haptic system is characterized by its sequential compilation of relevant information on the basis of successive exploratory procedures, each of which extracts specific object features (Lederman \& Klatzky, 1990, 1996). ${ }^{1}$

Sex differences do not usually occur in haptic tasks involving, for instance, the perception of the vertical, horizontal, and diagonal orientations (Gentaz \& Hatwell, $1995)$ or the identification of two- or three-dimensional nonrotated objects (Fagot, Lacreuse, \& Vauclair, 1993; Summers \& Lederman, 1990). Blindfolded participants have been reported to perform mental rotation operations based on hand (or finger) examination of tangible two-dimensional objects. These stimuli have consisted of alphanumeric (Carpenter \& Eisenberg, 1978; Hollins, 1986; Prather \& Sathian, 2002; Rösler, Röder, Heil, \& Hennighausen, 1993) and braille (Heller, Calcaterra, Green, \& de Lima, 1999) characters, as well as of a collection of meaningless forms (Dellantonio \& Spagnolo, 1990; Dodds, 1983; Röder, Rösler, \& Hennighausen, 1997; but see Klatzky, Golledge, Loomis, Cicinelli, \& Pellegrino, 1995). In the only two instances (with random forms) in which sex comparisons were conducted (Dodds, 1978; Marmor \& Zaback, 1976), the samples were small, and no significant differences were reported. No one has yet assessed haptic mental rotation with more complex objects that must be felt along all three
Euclidean axes. Those conditions are employed in the present experiment.

\section{Use of Real Three-Dimensional Stimuli}

With visual settings, one has the option of showing either actual three-dimensional objects or corresponding two-dimensional line drawings. ${ }^{2}$ Yet within the abundant literature on mental rotation with visual input, it appears to be solely in three studies that participants were presented with real three-dimensional objects. In Kaushall and Parsons's (1981) and Parsons's (1995) studies, the four-arm shapes (with at least one arm oriented along each Euclidean plane) conceived by Shepard and Metzler (1971) served as models for building simplified threearm styrofoam objects. Parsons contrasted mental rotation by using either real objects or the customary line drawings. In the rotation conditions relevant to the present case, the two sets of data looked equivalent. More informative was the experiment by McWilliams, Hamilton, and Muncer (1997), in which men and women were compared as they viewed either pairs of Shepard and Metzler's two-dimensional illustrations or pairs of threedimensional wooden replicas of the depicted objects. These authors found that men's higher accuracy was restricted to the first type of stimuli but failed to record response times under their untimed procedure. They also found that both sexes, but women in particular, were more accurate when shown actual objects instead of their two-dimensional portrayals (S. J. Muncer, personal communications, January 31 and March 6, 2000). This general effect of presentation format appears to occur mainly because only real objects can supply the perceptual cue defined by binocular disparity that is necessary for the visual system to interpret the depth plane in threedimensional scenes (Barbour \& Meyer, 1992).

In the present experiment, we investigated whether the male advantage found in the standard visual condition using two-dimensional illustrations of three-dimensional objects would occur in both a visual and a haptic condition involving real three-dimensional objects. The sequential processing underlying haptic perception (Lederman \& Klatzky, 1990, 1996) calls for a higher time limit in the haptic/object condition than in either visual condition. This time differential has been demonstrated in the mental rotation of simpler two-dimensional stimuli (Carpenter \& Eisenberg, 1978). Because it was not possible a priori to set a time limit so as to equate task difficulty in the present conditions with three-dimensional stimuli, both speed and accuracy were measured under an untimed procedure.

\section{Mental Rotation Strategies}

Information on processing strategies was also sought. In standard mental rotation conditions with visual input, two classes of strategies are generally identified: holistic strategies, in which the participants report trying to process the stimuli in a global fashion, and analytic strategies, 
in which the participants successively consider each stimulus part (Cooper, 1976; Shepard \& Cooper, 1982). The participants reporting the holistic strategy of mentally moving the whole three-dimensional stimulus show higher proficiency than do those relying on the analytic strategy of finding key stimulus features and encoding their relative positions (Schultz, 1991). In haptic settings, when feeling simpler two-dimensional forms, many participants report employing similar analytic strategies, relying on verbal labeling (Dodds, 1983) or mentally moving specific features (Dellantonio \& Spagnolo, 1990). Comparing both sexes in visual conditions, Peters et al. (1995) found that more men than women reported employing expedient holistic methods; the reverse is true for the mixed holistic-analytic strategy of performing hand movements to assist mental rotation. Similarly, Freedman and Rovegno (1981) found that high achievers, primarily men, indicated a greater use of holistic strategies and a lesser reliance on holistic-analytic and analytic (counting blocks) techniques, as compared with less competent participants. Exploiting a dual-task paradigm, Pezaris and Casey (1991) demonstrated that teenaged boys' achievement was less hindered by verbal interference than was girls', whereas the opposite occurred with visuospatial interference.

The literature thus suggests that, in the standard visual presentation condition, the holistic strategies preferred by men are more efficient than the analytic strategies preferred by women. With due caution toward retrospective self-reports (Ericsson \& Simon, 1993), in the present experiment, we examined whether the same selfreported preferences and the same difference in efficiency would be found when three-dimensional objects were either seen or felt.

\section{METHOD}

\section{Participants}

The participants were 60 men and 60 women who were each paid the equivalent of $\$ 4.50$ U.S. Between 20 and 30 years of age (mean age, 22.2 years), all were right-handed students enrolled in either undergraduate or graduate programs (in social science, French, or administration) at the Université de Montréal.

\section{Materials}

Handedness was established using a French translation of the Edinburgh Handedness Inventory (Oldfield, 1971).

Measurement of mental rotation ability was provided by using a random selection of 18 of the 24 items of the Mental Rotations Test (Vandenberg \& Kuse, 1978) as redrawn ${ }^{3}$ by Peters et al. (1995). ${ }^{4}$ Item order was the same as that in Peters et al.'s test. Each item was composed of five stimuli: a target on the left and four response choices (labeled A, B, C, and D) on the right. Two of these choices were identical to the target, although oriented differently.

In the visual/paper condition, photocopies of Peters et al.'s (1995) items were made with an enlargement factor of 2.25 to match the size of the stimuli in the other two conditions. Each item was glued to a white cardboard (43 cm long, $19.5 \mathrm{~cm}$ wide) that was maintained in a vertical position on a stand (see Figure 1). Whereas six items are illustrated on each paper sheet involved in Peters et al.'s test, only one item was shown on each cardboard sheet, to match presentation constraints in the other two conditions.
In the visual/object condition and the haptic/object condition, real three-dimensional objects were built to correspond to the illustrated stimuli and orientations in the visual/paper condition. Each object was composed of four arms of light wood of a matte beige color; the arms had been glued to one another to reproduce the required configuration. On each arm, 1-mm-wide grooves had been filled with a thin black rubber band that could be both seen (as could the black lines marking off adjacent cubes in the visual/paper condition) and felt. The rubber bands delimited 10 cubes $(1.9 \mathrm{~cm}$ per side); as in the visual/paper condition, each arm comprised between one and four cubes. The object was mounted on a wooden peg (10 cm high, $0.9 \mathrm{~cm}$ in diameter), inserted in a rectangular wooden base ( $91 \mathrm{~cm}$ long, $9 \mathrm{~cm}$ wide), to maintain it in a fixed orientation and, for objects tilted backward, to allow their bottom surfaces to be seen (partially) or felt, according to condition. For each item, the distance between the target stimulus and the first response choice was $26 \mathrm{~cm}$, whereas that between each response choice was $20.5 \mathrm{~cm}$ (see Figure 2). In order to establish color uniformity between the display and the immediate background similar to that in the visual/paper condition, a piece of beige cloth entirely covered the wall area located behind the table on which each item was placed.

On the basis of similar instruments employed by Freedman and Rovegno (1981), Schultz (1991), and Peters et al. (1995), a multiplechoice questionnaire was used to examine the strategies adopted during the test. In Question 1, the participant used a 1 (never) to 5 (always) scale to indicate how frequently he or she applied each of the seven strategies presented in Table 1. In the visual/paper and visual/object conditions in which the stimuli could be seen, the hands-off-object strategy was included among the questions; in the haptic/object condition, in which the stimuli had to be felt, it was replaced by the hands-on-object strategy. In each condition, the seven strategies were listed according to one of three random orders. Question 2 asked whether answers had been checked one or more times or not at all prior to being given. Finally, Question 3 involved a 1 (very easy) to 10 (very difficult) scale to evaluate how difficult the participant found the task.

\section{Procedure}

Recruited students answered the handedness questionnaire. Those with scores between 0 and 100 were considered to be righthanded and were invited to participate in further individual testing. Twenty men and 20 women were randomly assigned to each of the visual/paper, visual/object, or haptic/object conditions. In all three conditions, the mental rotation items remained concealed from the participant's view or reach both before and after task completion. The (female) experimenter instructed the participant to do his or her best to provide correct answers while working as fast as possible, although no time limit was imposed. ${ }^{5}$ Except while setting stimuli, the experimenter stood out of the participant's view. However, she was able to see the participant's hands. Standard office overhead lighting was used.

In the visual/paper condition, the stand was placed on the table, and the height of the seat used by the participant was adjusted so that his or her eyes were $75 \mathrm{~cm}$ away (in a straight line) from the center of the item displayed on the stand. With this distance, the stimuli were seen from a visual angle that varied between $3^{\circ}$ and $5^{\circ}$, depending on their height. ${ }^{6}$ Having set a two-section cardboard on the stand, the experimenter made clear to the participant that, although oriented differently, the five stimuli shown in the top section were identical and that these stimuli were different from the one shown in two different orientations in the bottom section. Then, with each of four practice items, the experimenter set a cardboard, similar to the real test items, on the stand. She informed the participant that he or she had to identify the two response choices that were the same as the target but oriented differently. Once he or she had voiced his or her choices, the experimenter indicated whether 


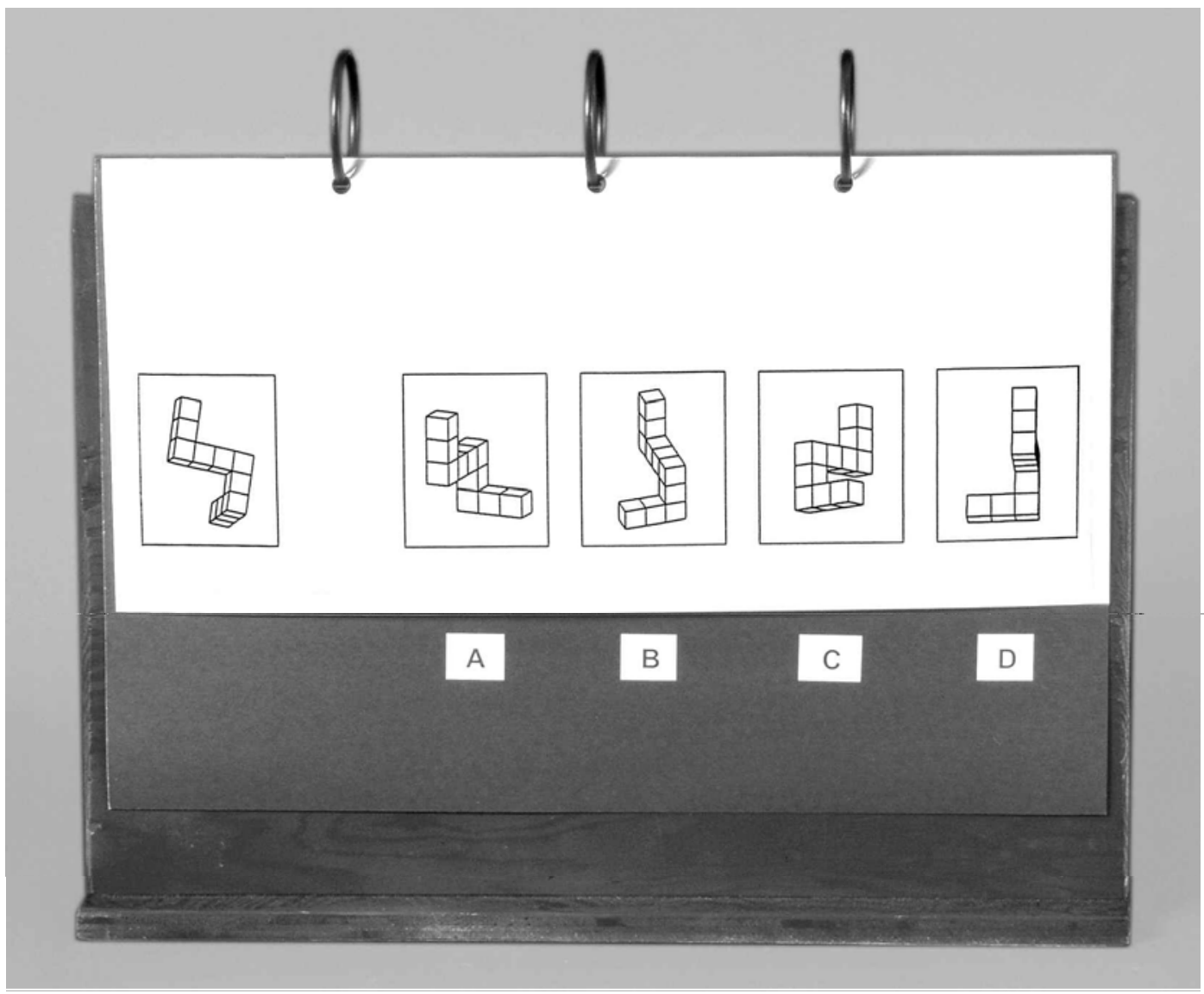

Figure 1. An item (No. 11 in Peters et al.'s, 1995, updated version) presented on a cardboard vertically set on a stand in the visual/paper condition. From left to right, the target stimulus and each of the four response choices (labeled A, B, C, and D).

they were correct or not; if they were incorrect, she supplied the correct choices.

The same procedure was applied in the first test block of nine items, except that no feedback was provided. On each item, the experimenter wrote down the participant's choices; she used a (silent) stopwatch to measure the time needed to make these choices from the moment the cardboard was set on the stand. ${ }^{7}$ A short rest involved a semantic fluency task: For $3 \mathrm{~min}$, the participant wrote on a sheet of paper the names of as many animals, fruits, and furniture as possible. The second block of nine items was presented according to the procedure employed in the first block. Finally, the participant answered the multiple-choice questionnaire on solving strategies. Overall, this condition was completed in approximately $30 \mathrm{~min}$.

In the visual/object condition, total completion time was the same as that in the previous condition. The procedure was also the same, save for the fact that, during all phases of the mental rotation task, the participant's eyes were $145 \mathrm{~cm}$ away (in a straight line) from the center of the three-dimensional items that were displayed on the table. This distance involved a visual angle varying between $3^{\circ}$ and $5^{\circ}$, depending on stimulus height, as in the visual/paper condition, since the retinal size of the stimuli affects the rate of mental rotation processes (Suzuki \& Nakata, 1988). The stopwatch was started from the moment the item was set on the table.

In the haptic/object condition, seat height was adjusted so that the participant's forearms rested on the table. The participant was to use only his or her hands to examine the stimuli. He or she was asked to put on opaque ski goggles that blocked even peripheral visual references. ${ }^{8} \mathrm{He}$ or she was first informed that one or both hands could be used to feel any stimulus and that two stimuli could be felt at the same time, one with each hand. Any stimulus could be touched as many times as wanted. The rest of the procedure was the same as that in the two previous conditions, except for the following points. At the beginning, once the participant had acknowledged that the first five stimuli were identical, these were moved back but could be easily reached while the two different stimuli were examined. Before the practice items, as well as before each nine-item block, the experimenter reiterated that the participant could feel any stimulus with one or both hands. Having set a given item on the table, she directed the participant's left hand toward the target and his or her right hand toward each response choice successively. The stopwatch was started from the moment the participant touched a stimulus (target or choice). The participant could either voice his or her answers or point to the selected response choices. He or she took off the goggles to perform the fluency task and to fill out the strategy questionnaire. This condition required between 35 and $65 \mathrm{~min}$, depending on the participant.

\section{RESULTS}

The level of significance was set at .05 in all statistical analyses. For an expected medium-size effect, power was deemed acceptable, as its level was .78 for the effect of sex and .68 for the effect of condition and the sex $X$ condition interaction. 


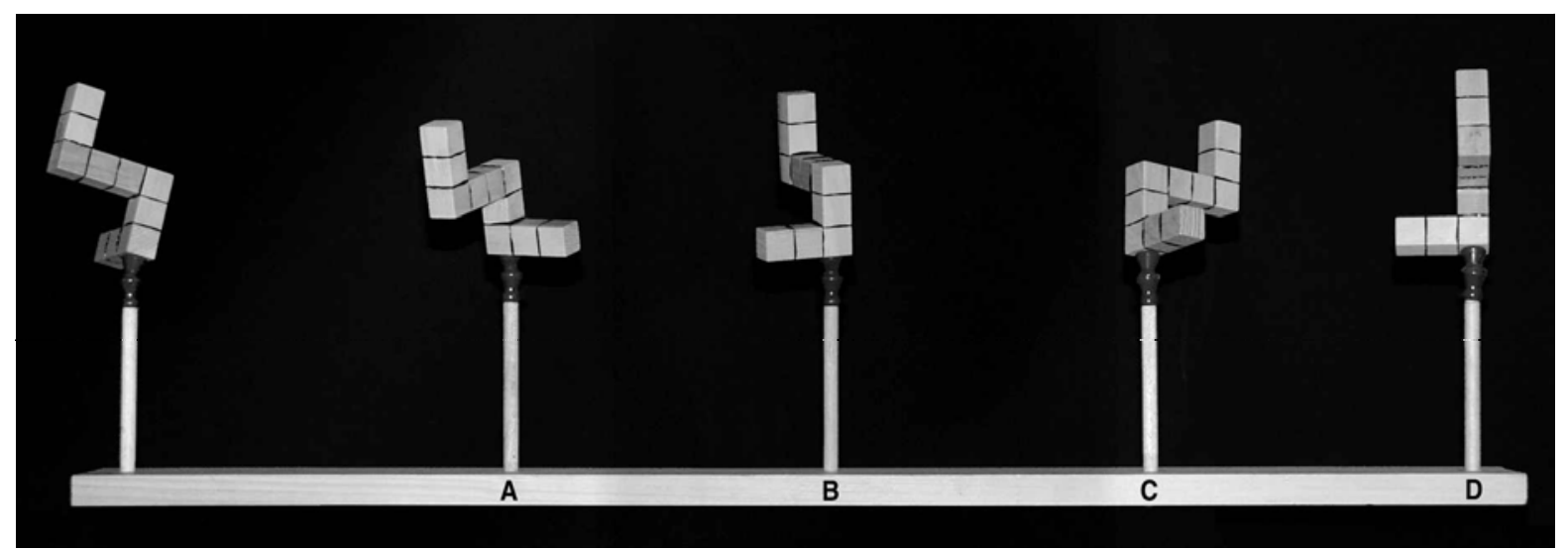

Figure 2. An item (No. 11 in Peters et al.s, 1995, updated version) composed of real three-dimensional objects mounted on a peg inserted in a base in the visual/object and haptic/object conditions. From left to right, the target stimulus and each of the four response choices (labeled $\mathrm{A}, \mathrm{B}, \mathrm{C}$, and D). To enhance photographic clarity, the beige cloth that covered the wall behind the objects was removed.

\section{Mental Rotation Performance}

In all three conditions, an item was scored as correct only if both stimuli identical to the target were selected (Peters et al., 1995). Since a preliminary analysis including test block as a variable showed no effect or interaction involving block, the results are presented collapsed over block. Table 2 reports the mean number of correct items (maximum, 18) completed by men and women in each condition, as well as the corresponding mean response times for the correct trials. Accuracy was high, averaging $85 \%$. Accuracy and response time were not significantly correlated (Pearson product-moment correlation) in any sex $\times$ condition group. The number of correct items was submitted to an analysis of variance according to a 2 (sex) $\times 3$ (condition) design. There was a significant effect of condition $\left[F(2,114)=9.25, M S_{\mathrm{e}}=\right.$ 58.91]. Tukey $B$ tests revealed that accuracy was higher in the visual/object condition than in the visual/paper condition and was lowest in the haptic/object condition. ${ }^{9}$ No other effects were significant.
An analysis of variance on response times showed an effect of sex $\left[F(1,114)=13.70, M S_{\mathrm{e}}=16,970.60\right]$ and condition $\left[F(2,114)=66.93, M S_{\mathrm{e}}=82,904.56\right]$. The interaction was not significant. Response times were shorter for men than for women; in addition, response times were shorter in the visual/object condition than in the visual/paper condition and were longest in the haptic/ object condition.

\section{Solving Strategies}

Table 3 presents the mean ratings supplied by men and women in each condition with regard to how frequently they believed that they had used each solving strategy while performing the task. For the hands-off-object strategy, which was relevant only in the visual/paper and visual/ object conditions, the ratings were submitted to an analysis of variance according to a $2(\operatorname{sex}) \times 2$ (condition) design; for the hands-on-object strategy, which was possible only in the haptic/object condition, a one-way 2 (sex) design was employed. Separately for each remaining

Table 1

Characterization of Mental Rotation Strategies and Corresponding Response Choices Offered in the Multiple Choice Questionnaire

\begin{tabular}{|c|c|c|}
\hline General Type & Nature & Response Choice \\
\hline \multirow[t]{2}{*}{ Holistic } & 1. Move object & "I pictured the target as moving." \\
\hline & 2. Move self & "I imagined myself moving around the target." \\
\hline \multirow[t]{2}{*}{ Holistic-Analytic } & $\begin{array}{l}\text { Hand use: } \\
\text { 1. Hands off object }\end{array}$ & "I used my hands to help me visualize the target."* \\
\hline & 2. Hands on object & $\begin{array}{l}\text { "I compared my hand movements on the target with } \\
\text { those on the response choices."** }\end{array}$ \\
\hline \multirow[t]{2}{*}{ Analytic } & 1. Key feature & $\begin{array}{l}\text { "I looked for a key feature in the target and checked } \\
\text { which response choices had the same feature." }\end{array}$ \\
\hline & 2. Describe object & $\begin{array}{l}\text { "I described the target to myself and then checked } \\
\text { which response choices matched my description." }\end{array}$ \\
\hline \multirow[t]{2}{*}{ No strategy } & 1. Guess & "I guessed which were the correct response choices." \\
\hline & 2. Know & "I just knew which were the correct response choices." \\
\hline
\end{tabular}

*Visual/paper and visual/object conditions. **Haptic condition. 
Table 2

Mean Number of Correct Items (Maximum, 18) and Response Times (in Seconds, With Standard Deviations) for Men and Women in Each Condition

\begin{tabular}{|c|c|c|c|c|c|c|}
\hline \multirow[b]{3}{*}{ Sex } & \multicolumn{6}{|c|}{ Condition } \\
\hline & \multicolumn{2}{|c|}{ Visual/Paper } & \multicolumn{2}{|c|}{ Visual/Object } & \multicolumn{2}{|c|}{ Haptic/Object } \\
\hline & $M$ & $S D$ & $M$ & $S D$ & $M$ & $S D$ \\
\hline \multicolumn{7}{|c|}{ Number of Correct Items } \\
\hline Men & 15.00 & 2.38 & 16.70 & 0.92 & 15.04 & 2.12 \\
\hline Women & 15.10 & 2.38 & 16.50 & 1.54 & 13.38 & 4.38 \\
\hline \multicolumn{7}{|c|}{ Response Time } \\
\hline Men & 27.33 & 12.18 & 16.71 & 7.51 & 81.69 & 46.87 \\
\hline Women & 40.24 & 17.49 & 28.88 & 18.25 & 124.72 & 61.39 \\
\hline
\end{tabular}

strategy, a $2(\operatorname{sex}) \times 3$ (condition) design was used. None of these analyses disclosed a significant sex $\times$ condition interaction. Except for the guess and know strategies, there were, however, some effects of sex and condition.

There were significant effects of sex for each of the hands-on-object $\left[F(1,38)=4.72, M S_{\mathrm{e}}=7.23\right]$, key feature $\left[F(1,114)=4.61, M S_{\mathrm{e}}=8.01\right]$, and describe object $\left[F(1,114)=4.63, M S_{\mathrm{e}}=6.53\right]$ strategies, with women reporting higher use of these strategies.

There was a significant condition effect for the move object strategy $\left[F(2,114)=3.17, M S_{\mathrm{e}}=3.91\right]$. Tukey $B$ comparisons showed the highest reported use in the visual/ paper condition and the lowest in the haptic/object condition. There was a significant effect of condition for the move self strategy $\left[F(2,114)=4.04, M S_{\mathrm{e}}=5.73\right]$, with a higher reported use in the visual/paper condition than in the haptic/object condition. There was a significant effect of condition for the hands-off-object strategy $[F(1,76)=$ $10.45, M S_{\mathrm{e}}=9.11$, with a higher reported use in the visual/ paper condition than in the visual/object condition. Finally, there was a significant effect of condition for the key feature strategy $\left[F(2,114)=5.88, M S_{\mathrm{e}}=10.23\right]$, with a higher reported use in the haptic/object condition than in the two visual conditions.

Table 4 reports the number of men and women who, in each condition, indicated that they had checked their an- swers prior to giving them. A chi-square test of independence revealed that the sex and condition factors interacted $\left[x^{2}(2, N=118)=6.64\right]$. Whereas response checking did not differ between men and women in the two visual conditions, more women than men checked their answers in the haptic/object condition $\left[x^{2}(1, N=40)=5.38\right]$. Table 4 also presents the mean difficulty ratings attributed to the task by men and women in each condition. The ratings were submitted to an analysis of variance according to a 2 (sex) $\times 3$ (condition) design. No significant interaction was found. There was a significant effect of sex $\left[F(1,113)=20.01, M S_{\mathrm{e}}=62.30\right]$. Relative to men, women evaluated the task as more difficult. There was also a significant effect of condition $\left[F(2,113)=7.10, M S_{\mathrm{e}}=\right.$ 22.11]. The participants in the haptic/object condition evaluated the task as more difficult, as compared with those in either visual condition.

\section{DISCUSSION}

The present results revealed relatively high accuracy levels overall. Although men did not supply significantly more correct answers than did women across the three conditions, they needed, on average, less time to carry out the mental rotation of the structures illustrated in Vandenberg and Kuse's (1978) items. Regardless of sex, performance was both faster and more accurate in the visual/object than in the visual/paper condition and was lowest in the haptic/object condition. Self-reported processing strategies also showed only main effects.

\section{Sex Differences}

With untimed testing, men displayed a processing speed advantage under the visual/paper format. This result is in accordance with conclusions drawn from metaanalyses of accuracy-based results derived from Shepard and Metzler's (1971) untimed procedure (Linn \& Petersen, 1985; Voyer et al., 1995). However, the habitual male superiority in accuracy with Vandenberg and Kuse's (1978) paper-and-pencil items under timed testing (Voyer et al., 1995) did not occur here with untimed test-

Table 3

Mean Ratings (and Standard Deviations) Regarding Use Frequency of Each Solving Strategy in Men and Women From Each Condition

\begin{tabular}{|c|c|c|c|c|c|c|c|c|c|c|c|c|c|c|c|c|}
\hline \multirow[b]{3}{*}{ Condition } & \multicolumn{16}{|c|}{ Strategy } \\
\hline & \multicolumn{2}{|c|}{$\begin{array}{l}\text { Move } \\
\text { Object }\end{array}$} & \multicolumn{2}{|c|}{$\begin{array}{l}\text { Move } \\
\text { Self }\end{array}$} & \multicolumn{2}{|c|}{$\begin{array}{c}\text { Hands Off } \\
\text { Object }\end{array}$} & \multicolumn{2}{|c|}{$\begin{array}{c}\text { Hands On } \\
\text { Object }\end{array}$} & \multicolumn{2}{|c|}{$\begin{array}{c}\text { Key } \\
\text { Feature }\end{array}$} & \multicolumn{2}{|c|}{$\begin{array}{c}\text { Describe } \\
\text { Object }\end{array}$} & \multicolumn{2}{|c|}{ Guess } & \multicolumn{2}{|c|}{ Know } \\
\hline & $M$ & $S D$ & $M$ & $S D$ & $M$ & $S D$ & $M$ & $S D$ & $M$ & $S D$ & $M$ & $S D$ & $M$ & $S D$ & $M$ & $S D$ \\
\hline \multicolumn{17}{|c|}{ Men } \\
\hline Visual/paper & 4.35 & 1.04 & 2.00 & 1.49 & 1.70 & 0.98 & - & - & 1.70 & 0.92 & 3.40 & 1.14 & 1.35 & 0.75 & 1.50 & 0.51 \\
\hline Visual/object & 4.40 & 0.75 & 1.90 & 0.97 & 1.25 & 0.55 & - & - & 1.60 & 1.14 & 3.25 & 1.25 & 1.25 & 0.72 & 1.70 & 0.87 \\
\hline Haptic/object & 3.60 & 1.50 & 1.25 & 0.91 & - & - & 3.20 & 1.40 & 2.80 & 1.58 & 3.30 & 1.30 & 1.55 & 1.05 & 1.40 & 0.68 \\
\hline \multicolumn{17}{|c|}{ Women } \\
\hline Visual/paper & 4.25 & 0.79 & 2.00 & 1.45 & 2.25 & 1.33 & - & - & 2.35 & 1.46 & 1.70 & 1.03 & 1.35 & 0.75 & 1.55 & 0.95 \\
\hline Visual/object & 3.60 & 1.27 & 1.90 & 0.97 & 1.35 & 0.67 & - & - & 2.35 & 1.35 & 3.60 & 1.23 & 1.20 & 0.41 & 1.40 & 0.60 \\
\hline Haptic/object & 3.75 & 1.12 & 1.35 & 0.99 & - & - & 4.05 & 1.05 & 2.95 & 1.36 & 4.05 & 1.15 & 1.40 & 0.60 & 1.30 & 0.47 \\
\hline
\end{tabular}


Table 4

For Men and Women in Each Condition, Numbers and Percentages of Participants Who Reported Having Checked Their Answers Prior to Giving Them and Mean Task Difficulty Ratings and Standard Deviations

\begin{tabular}{cllllll}
\hline & & \multicolumn{2}{c}{ Checked Answer } & & \multicolumn{2}{c}{ Difficulty Rating } \\
Condition & Sex & $N$ & $\%$ & & $M$ & $S D$ \\
\hline Visual/paper & men & $12^{*}$ & 63 & & 5.00 & 2.34 \\
& women & 11 & 55 & & 6.15 & 1.50 \\
Visual/object & men & $10^{*}$ & 53 & & 4.16 & 1.57 \\
& women & 14 & 70 & & 5.40 & 1.47 \\
Haptic/object & men & 9 & 45 & & 5.30 & 2.18 \\
& women & 17 & 85 & & 7.25 & 1.25 \\
\hline
\end{tabular}

*One of the 20 participants did not answer.

ing. Nor has it always been obtained with Shepard and Metzler's procedure (Linn \& Petersen, 1985; Voyer et al., 1995). In untimed settings similar to the present one, other authors have reported inconsistent outcomes, using similar items: Whereas Goldstein et al. (1990) and Voyer (1997) found no significant sex differences in accuracy, Resnick (1993) and Masters (1998) observed higher scores in men. In the visual/paper condition, three procedural changes imposed by constraints of the conditions involving real objects may have helped increase accuracy among lower performers, generally women (Voyer et al., 1995), thus canceling the sex difference. First, the participants were presented with one item at a time, instead of being given a booklet with several items per page; this may have improved concentration. Second, with respect to the participant, the stimuli were presented in the frontoparallel plane, as opposed to perpendicularly (i.e., lying flat on the table); this may have facilitated the required mental operations, as has been suggested by Parsons' (1995) work. Third, answers were supplied directly to the experimenter, rather than anonymously written in the booklet; this may have enhanced motivation to perform well.

The expected men's speed advantage in the visual/paper condition was replicated in both conditions with real objects. Indeed, none of these conditions exerted a differential impact on men's and women's proficiency. In the visual/object condition, both sexes benefited to the same extent from depth cues' being easier to extract than in the visual/paper condition (Barbour \& Meyer, 1992). These more accessible cues were not more advantageous for women, contrary to McWilliams et al.'s (1997) observation on accuracy (S. J. Muncer, personal communications, January 31 and March 6, 2000). Still, in the visual/ object condition, women gained enough speed to apparently equal that of the men in the visual/paper condition (see Table 2). Conversely, in the haptic/object condition, both sexes were impaired to the same extent by the necessity of grasping the stimulus shape and orientation through demanding sequential hand and finger exploration (Lederman \& Klatzky, 1990, 1996).

Although Logie (1995) has highlighted the critical role played by visuospatial working memory in standard, visual mental rotation tasks, Vecchi, Phillips, and Cornoldi (2001) have recently reviewed evidence that suggests a possible male superiority in this type of working memory capacity. The possibility that men draw on a greater ability to encode, memorize, and process complex concurrent spatial data would explain why the extent of their greater proficiency in three-dimensional mental rotation was unaffected by the present type of stimulus manipulations. Consistent with this is the fact that, irrespective of condition, men judged the task to be less difficult than women did. In addition, men reported having used less often than women analytic strategies that apply to segmented information, such as verbally describing the objects or focusing on their key features. In the taxing haptic/object condition, men also declared less frequent response checking and hand movement assistance than did women. In both visual conditions, however, no significant sex differences were detected in response checking. If this self-report measure validly assessed cautiousness, this variable did not contribute to the sex difference in speed. By contrast, sex differences are usually not found in those haptic spatial tasks (e.g., Gentaz \& Hatwell, 1995; Robert et al., 1994; Summers \& Lederman, 1990; Walker, 1972) that demand less in terms of working memory resources because they do not require the transformation of the encoded information. In an untimed visuospatial working memory task in which twodimensional stimuli had to be mentally rotated, LoringMeier and Halpern (1999) obtained results that parallel the present ones: Speed was higher for men than for women, but accuracy was comparable for both sexes. However, more research is needed, because the literature is mixed. With Vandenberg and Kuse's (1978) timed test, mental rotation accuracy was reported to be linked with achievement in one spatial span task among women only and in another one among men as well (Savoie, Robert, Chevrier, \& Hélie, 2001).

\section{Presentation Modality Effects}

Independent of the sex factor, the two real threedimensional object conditions had opposite effects on achievement, as compared with the standard presentation of two-dimensional line drawings of the same objects. On the one hand, showing full three-dimensional objects was beneficial, since it increased accuracy and reduced response time. This is consistent with similarly improved mental rotation accuracy (S. J. Muncer, personal communications, January 31 and March 6, 2000) in McWilliams et al.'s (1997) untimed procedure (under which response time was not recorded). In the present study, seeing real objects probably accelerated both the analysis of the global configurations of the stimuli and the identification of the exact orientations of their four arms. This would have been particularly crucial with respect to the depth plane, since two-dimensional pictures lack the binocular disparity cue, thus making the interpretation of three-dimensional layouts more difficult (Barbour \& Meyer, 1992). In correspondence with such 
facilitated visual processing, reliance on hand support to visualize the stimuli was less frequently mentioned in the visual/object than in the visual/paper condition. Yet, at variance with the idea that the visual/object condition provided a more supportive rotation setting, this condition was related to a lower reporting of picturing moving stimuli; perhaps it made the participants less aware, due to their greater speed, of having often adopted this efficient strategy.

On the other hand, feeling real but nonvisible threedimensional objects had an adverse effect, since it decreased accuracy ${ }^{10}$ and increased response time. This follows from haptic processing's being necessarily more piecemeal and step bound than visual analysis (Kennedy et al., 1991; Lederman \& Klatzky, 1990, 1996). Detailed investigations of the serial course of haptic exploratory procedures, each of which picks up only a portion of the available cues, have revealed that haptic processing assesses the material properties of the felt object first (e.g., its texture and temperature) and then the surface features (e.g., its edges and continuity); the encoding of spatial characteristics per se, such as relative orientation or three-dimensional contour traits comes relatively later (Lederman \& Klatzky, 1997). Hence, a clear representation of overall configuration and position ultimately emerges after a sequence of specialized hand and finger movements, indicating that the haptic system is less effective than the visual system in detecting the more global aspects of object geometry (Lakatos \& Marks, 1999). In keeping with the present performance data, the participants perceived the mental rotation task to be more difficult in the haptic/object condition than in either visual condition. In addition, in the former condition, selfreported frequency regarding use of analytic approaches, such as focusing on local key features, was higher than in both visual conditions, whereas that involving holistic methods, such as mentally moving oneself around the stimuli, was lower.

\section{Conclusion}

By employing Vandenberg and Kuse's (1978) items in an untimed setting, the aim of the present experiment was to establish whether the manipulation of input and type of processing would affect the classic male advantage in mental rotation. The manipulation was clearly effective in modifying performance level; yet its impact was similar in both sexes. Men's higher response speed (Linn \& Petersen, 1985; Voyer et al., 1995) was maintained across conditions. A further comparison of visual and haptic conditions could be explored with mental rotation tasks that produce less refractory sex differences. This might involve presenting simpler, two-dimensional objects that would, nonetheless, be complex enough to generate a substantial male advantage in the standard visual context (see Collins \& Kimura, 1997). It would also be interesting to determine whether the sex difference is canceled in a dual setting in which real three-dimensional objects are both seen and felt. For the benefit of lower performers, primarily women, this two-pronged condition could create richer multifaceted representations, as has been suggested by a recent finding showing that the front views of three-dimensional objects somewhat resembling those conceived by Shepard and Metzler (1971) are best recognized by the eye and that their backs are best identified by the hand (Newell, Ernst, Tjan, \& Bülthoff, 2001).

\section{REFERENCES}

Amponsah, B. (2000). A comparison of sex differences in visual-spatial performance from preadolescence to adulthood in Ghana and Norway. South African Journal of Psychology, 30, 25-31.

Barbour, C. G., \& Meyer, G. W. (1992). Visual cues and pictorial limitations for computer generated photo-realistic images. Visual Computer, 9, 151-165.

Bülthoff, H. H., \& Edelman, S. (1992). Psychophysical support for a two-dimensional view interpolation theory of object recognition. Proceedings of the National Academy of Sciences, 89, 60-64.

Carpenter, P. A., \& Eisenberg, P. (1978). Mental rotation and the frame of reference in blind and sighted individuals. Perception \& Psychophysics, 23, 117-124.

Collins, D. W., \& Kimura, D. (1997). A large sex difference on a twodimensional mental rotation task. Behavioral Neuroscience, 111, 845849.

Cooper, L. A. (1976). Individual differences in visual comparison processes. Perception \& Psychophysics, 19, 433-444.

Dellantonio, A., \& Spagnolo, F. (1990). Mental rotation of tactual stimuli. Acta Psychologica, 73, 245-257.

DodDs, A. G. (1978). Hemispheric differences in tactuo-spatial processing. Neuropsychologia, 16, 247-249.

DodDs, A. G. (1983). Mental rotation and visual imagery. Journal of Visual Impairment \& Blindness, 77, 16-18.

ERICSSON, K. A., \& SimOn, H. A. (1993).Protocol analysis: Verbal reports as data. Cambridge, MA: MIT Press.

FAgot, J., LACREUSE, A., \& VAUClair, J. (1993). Haptic discrimination of nonsense shapes: Hand exploratory strategies but not accuracy reveal laterality effects. Brain \& Cognition, 21, 212-225.

Freedman, R. J., \& Rovegno, L. (1981). Ocular dominance, cognitive strategy, and sex differences in spatial ability. Perceptual \& Motor Skills, 52, 651-654.

Gentaz, E., \& Hatwell, Y. (1995). The haptic "oblique effect" in children's and adults' perception of orientation. Perception, 24, 631-646.

Goldstein, D., Haldane, D., \& Mitchell, C. (1990). Sex differences in visual-spatial ability: The role of performance factors. Memory \& Cognition, 18, 546-550.

Hatwell, Y. (1990). Spatial perception by eyes and hand: Comparison and intermodal integration. In C. Bard, M. Fleury, \& L. Hay (Eds.), Development of eye-hand coordination across the life span (pp. 99132). Columbia: University of South Carolina Press.

HeLler, M. A. (1993). Influence of visual guidance on braille recognition: Low lighting also helps touch. Perception \& Psychophysics, 54, 675-681.

Heller, M. A., Calcaterra, J. A., Green, S. L., \& De Lima, J. (1999). The effect of orientation on braille recognition in persons who are sighted and blind. Journal of Visual Impairment \& Blindness, 93, 416-418.

Hollins, M. (1986). Haptic mental rotation: More consistent in blind subjects? Journal of Visual Impairment \& Blindness, 80, 950-952.

Humphrey, G. K., \& KHAN, S. C. (1992). Recognizing novel views of three-dimensional objects. Canadian Journal of Psychology, 46, 170-190.

Kaushall, P., \& Parsons, L. M. (1981). Optical information and practice in the discrimination of three-dimensional mirror-reflected objects. Perception, 10, 545-562.

Kennedy, J. M., Gabias, P., \& Nicholls, A. (1991). Tactile pictures. In M. A. Heller \& W. Schiff (Eds.), The psychology of touch (pp. 263299). Hillsdale, NJ: Erlbaum. 
Klatzky, R. L., Golledge, R. G., Loomis, J. M., Cicinelli, J. G., \& Pellegrino, J. W. (1995). Performance of blind and sighted persons on spatial tasks. Journal of Visual Impairment \& Blindness, 89, 7082.

LAKatos, S., \& Marks, L. E. (1999). Haptic form perception: Relative salience of local and global features. Perception \& Psychophysics, 61, 895-908.

Lederman, S. J., \& KlatzKy, R. L. (1990). Haptic exploration and object representation. In M. Goodale (Ed.), Vision and action: The control of grasping (pp. 98-109). Norwood, NJ: Ablex.

Lederman, S. J., \& KLATZKY, R. L. (1996). Action for perception: Manual exploratory movements for haptically processing objects and their features. In A. M. Wing, P. Haggard, \& J. R. Flanagan (Eds.), Hand and brain: The neurophysiologyand psychology of hand movements (pp. 431-446). San Diego: Academic Press.

Lederman, S. J., \& KLATZKY, R. L. (1997). Relative availability of surface and object properties during early haptic processing. Journal of Experimental Psychology: Human Perception \& Performance, 23, 1680-1707.

Lederman, S. J., \& Klatzky, R. L. (1998). The hand as a perceptual system. In K. J. Connolly (Ed.), The psychobiology of the hand (pp. 16-35). London: Mac Keith Press.

Li, C., Nuttall, R. L., \& Zhu, W. (1999). Writing Chinese characters and success on mental rotation test. Perceptual \& Motor Skills, 88, 1261-1270.

Linn, M. C., \& Petersen, A. C. (1985). Emergence and characterization of sex differences in spatial ability: A meta-analysis. Child Development, 56, 1479-1498.

LogIe, R. H. (1995). Visuo-spatial working memory. Hillsdale, NJ: Erlbaum.

Loomis, J. M., \& Lederman, S. J. (1986). Tactual perception. In K. R. Boff, L. Kaufman, \& J. P. Thomas (Eds.), Handbook of perception and human performance: Vol. II. Cognitive processes and performance (pp. 31.1-31.41). New York: Wiley.

Loring-Meier, S., \& HALPERN, D. F. (1999). Sex differences in visuospatial working memory: Components of cognitive processes. Psychonomic Bulletin \& Review, 6, 464-471.

Mann, V. A., Sasanuma, S., Sakuma, N., \& Masaki, S. (1990). Sex differences in cognitive abilities: A cross-cultural perspective. Neuropsychologia, 28, 1063-1077.

MARMOR, G. S., \& ZABACK, L. A. (1976). Mental rotation by the blind: Does mental rotation depend on visual imagery? Journal of Experimental Psychology: Human Perception \& Performance, 2, 515-521.

Masters, M. S. (1998). The gender difference on the Mental Rotations Test is not due to performance factors. Memory \& Cognition, 26, 444448.

Masters, M. S., \& SAnders, B. (1993). Is the gender difference in mental rotation disappearing? Behavior Genetics, 23, 337-341.

McWilliams, W., Hamilton, C. J., \& Muncer, S. J. (1997). On mental rotation in three dimensions. Perceptual \& Motor Skills, 85, 297 298.

Newell, F. N., Ernst, M. O., Tuan, B. S., \& Bülthoff, H. H. (2001). Viewpoint dependence in visual and haptic object recognition. Psychological Science, 12, 37-42.

OLDFIELD, R. C. (1971). The assessment and analysis of handedness: The Edinburgh Inventory. Neuropsychologia, 9, 97-117.

PARSONS, L. M. (1995). Inability to reason about an object's orientation using an axis and angle of rotation. Journal of Experimental Psychology: Human Perception \& Performance, 21, 1259-1277.

Peters, M., Laeng, B., Latham, K., Jackson, M., Zaiyouna, R., \& Richardson, C. (1995). A redrawn Vandenberg and Kuse Mental Rotations Test: Different versions and factors affect performance. Brain \& Cognition, 28, 39-58.

Pezaris, E., \& CASEY, M. B. (1991). Girls who use "masculine" problemsolving strategies on a spatial task: Proposed genetic and environmental factors. Brain \& Cognition, 17, 1-22.

Prather, S. C., \& Sathian, K. (2002). Mental rotation of tactile stimuli. Cognitive Brain Research, 14, 91-98.

Proffitt, D. R., Bhalla, M., Gossweiler, R., \& Midgett, J. (1995). Perceiving geographical slant. Psychonomic Bulletin \& Review, 2, 409-428.
RESNICK, S. M. (1993). Sex differences in mental rotations: An effect of time limit? Brain \& Cognition, 21, 71-79.

Robert, M., \& LongPré, S. (2002). Sensory and postural input in the occurrence of a gender difference in orienting liquid surfaces. Manuscript submitted for publication.

Robert, M., Pelletier, J., St-Onge, R., \& Berthiaume, F. (1994). Women's deficiency in water-level representation: Present in visual conditions yet absent in haptic contexts. Acta Psychologica, 87, 19-32.

Röder, B., Rösler, F., \& Hennighausen, E. (1997). Different cortical activation patterns in blind and sighted humans during encoding and transformation of haptic images. Psychophysiology, 34, 292-307.

Rösler, F., Röder, B., Heil, M., \& Hennighausen, E. (1993). Topographic differences of slow event-related brain potentials in blind and sighted adult human subjects during haptic mental rotation. Cognitive Brain Research, 1, 145-159.

Savoie, N., Robert, M., Chevrier, E., \& Hélie, S. (2001, June). Are there gender differences in verbal and visuo-spatial working memory? Poster session presented at the annual meeting of the Canadian Society for Brain, Behaviour, and Cognitive Science, Quebec City.

Schultz, K. (1991). The contribution of solution strategy to spatial performance. Canadian Journal of Psychology, 45, 474-491.

Shepard, R. N., \& CoOper, L. A. (1982). Mental images and their transformations. Cambridge, MA: MIT Press.

Shepard, R. N., \& Metzler, J. (1971). Mental rotation of threedimensional objects. Science, 171, 701-703.

Summers, D. C., \& Lederman, S. J. (1990). Perceptual asymmetries in the somatosensory system: A dichhaptic experiment and critical review of the literature from 1929 to 1986. Cortex, 26, 201-226.

Suzuki, K., \& NAKata, Y. (1988). Does the size of figures affect the rate of mental rotation? Perception \& Psychophysics, 44, 76-80.

Vandenberg, S. G., \& Kuse, A. R. (1978). Mental rotations, a group test of three-dimensional spatial visualization. Perceptual \& Motor Skills, 47, 599-604.

Vecchi, T., Phillips, L. H., \& CoRnoldi, C. (2001). Individual differences in visuo-spatial memory. In M. Denis, R. H. Logie, M. de Vega, \& J. Emmelkamp (Eds.), Imagery, language, and visuo-spatial thinking (pp. 29-58). Hove, U.K.: Psychology Press.

VOYER, D. (1997). Scoring procedure, performance factors, and magnitude of sex differences in spatial performance. American Journal of Psychology, 110, 259-276.

VOYER, D. (2001, June). The effect of performance factors on sex differences in paper-and-pencil tests of mental rotation: A meta-analysis. Paper presented at the meeting of the Canadian Society for Brain, Behavior, and Cognitive Science, Quebec City.

Voyer, D., Voyer, S. D., \& Bryden, M. P. (1995). Magnitude of sex differences in spatial abilities: A meta-analysis and consideration of critical variables. Psychological Bulletin, 117, 250-270.

WALKer, J. T. (1972). Tactual field dependence. Psychonomic Science, 26, 311-313.

\section{NOTES}

1. Sequential processes are also at work in the visual system. Taking place at a much faster speed, however, they may give the impression of being almost simultaneous (Kennedy, Gabias, \& Nicholls, 1991).

2 . Another possibility involves photog raphic representations of threedimensional stimuli (e.g., Bülthoff \& Edelman, 1992; Humphrey \& Khan, 1992). To our knowledge, the mental rotation of such representations has not been compared with that of corresponding line drawings.

3. This computer-assisted operation had become necessary following a deterioration of the original illustrations with repeated photocopying.

4. The selected items were Items $1,3,5,7,8,9,11,12,13,15,16$, $17,19,20,21,22,23$, and 24 in Peters et al.'s (1995) updated test. The aim of the reduction in number of items was to avoid an overly long testing time and the resulting fatigue in the haptic/object condition, given that Carpenter and Eisenberg (1978) had shown that the haptic mental rotation of two-dimensional stimuli requires more than twice the time needed in a normal visual condition. Similarly, the concentration demanded to haptically execute one moderately difficult (by visual standards) three-dimensional item was judged to be high during pilot testing with 10 students. 
5. It was deemed that, in the haptic/object condition, imposing unduly high processing demands should be avoided by not informing the participants that response times were being recorded. The same restriction had to apply in the other two conditions. Similarly, in all conditions, the stopwatch was hidden from view, since it could not be shown in the haptic/object condition.

6. Such an angle variation was the same as that in Peters et al.'s (1995) paper-and-pencil test under a normal $40-\mathrm{cm}$ reading distance between the participant and the stimuli.

7. After having expressed their choices, across conditions, a few participants hesitated and considered changing their answers. In these rare cases (i.e., $0.01 \%$ of all the answers), the stopwatch was reset. If the participant actually changed his or her answers, the previous answers were canceled. However, irrespective of the answers' being changed or not, total time, from item presentation to final choices, was recorded.

8. This setup was preferred over simply screening the stimuli from the participant's view, because, as is suggested by Heller's (1993) findings on the haptic recognition of rotated braille characters, extraneous visual stimulation from the surrounding environment may interfere with the ability of sighted individuals to mentally rotate visual representations of haptic input.

9. A similar outcome occurred with the less stringent scoring of merely totaling the number of correctly selected stimuli across items (maximum, 36; Goldstein et al., 1990). There was an effect of condition $\left[F(2,114)=8.27, M S_{\mathrm{e}}=69.61\right]$, with higher accuracy in the visual/object condition than in both other conditions.

10. However, when more lenient scoring was applied, accuracy was not significantly lower in the haptic/object than in the visual/paper condition. This suggests that object shape and orientation are truly not easily discerned in Shepard and Metzler's (1971) two-dimensional illustrations. It also exemplifies the great adeptness of the haptic system in processing the spatial features of complex stimuli. As was suggested by an anonymous reviewer, reducing the size of the object to be felt could also improve performance through facilitating a more holistic processing.

(Manuscript received June 21, 2002;

revision accepted for publication April 26, 2003.) 